\title{
Getting the Most from Classroom Simulations: Strategies for Maximizing Learning Outcomes
}

Timothy Wedig, University of Illinois at Urbana-Champaign

ABSTRACT Classroom simulations can make a significant contribution to learning outcomes in political science courses, provided that they are firmly linked to course content and learning objectives. This article offers a step-by-step decision framework for instructors seeking to use simulations as a core component of their courses, including selection of an exercise, pre-simulation preparation, instructor role during a simulation, and techniques for debriefing after the exercise. Options such as online and face-to-face, synchronous and asynchronous, distributed and single classroom, and individual and team formats are compared, with a focus on their associated learning outcomes.

\section{INTRODUCTION}

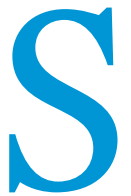

imulations offer students the opportunity to apply course content in an active learning environment, provide a laboratory aspect that is generally missing from political science classrooms, and incorporate opportunities to succeed with a variety of student learning styles. Simulations can provide motivation for students by offering competitive stakes beyond grades, such as peer recognition and collaborative work environments, while clarifying difficult concepts through active participation. However, while classroom simulations can be useful pedagogical tools, they lose much of their effectiveness if they are not linked to the content and goals of the course itself.

To maximize learning outcomes from a simulation exercise, it is essential that an instructor carefully consider the framework into which the exercise will be placed to ensure its full integration into the course. Simulations that are not well-integrated into the course (i.e., stand-alone or add-on activities) risk becoming distractions by breaking the course's momentum rather than reinforcing learning objectives. From my conversations with instructors at conferences and workshops, it is apparent that this factor is behind much of the anecdotal evidence that discourages instructors from using simulations more often or, in many cases, at all. Fortunately, there is a generalizable framework that instructors can use to ensure that this integration occurs, so that they may maximize the benefit of simulations in the classroom and enhance student learning.

I have designed, facilitated, and supported simulation exercises in a variety of educational and professional environments

Timothy Wedig is a visiting lecturer in global studies at the University of Illinois at Urbana-Champaign. His research and teaching interests include diplomacy and negotiation, international humanitarian intervention, and the use of the Internet by political organizations and social movements. He can be reached at twedig@illinois.edu. for over a decade. This article summarizes lessons learned throughout the years and offers a set of best-practice recommendations for faculty who seek to use simulations more effectively in their courses. I focus on the three stages of an in-class simulation: presimulation preparation, interaction and support during the exercise, and the post-simulation debriefing process. Each of these three phases is important for maximizing the learning return for a classroom simulation, and this article presents a series of approaches to do so that are drawn from classroom and simulation design experience.

\section{BENEFITS OF SIMULATIONS}

It is critical for a classroom simulation to support larger course objectives-simulation for simulation's sake is rarely effective as a pedagogical tool. For understandable reasons, a simulation that has no direct linkage to course material is often poorly received by students, resulting in a flat and uninteresting experience for all involved. This situation not only misses important teaching opportunities, but it can also result in lost momentum for the course in general. A simulation should support course learning objectives in a clear and direct way; if you as the instructor are unable to make those connections clear for yourself, the students will certainly not be able to either. Implemented well, however, simulation exercises can be a centerpiece in the political science classroom. In considering the best simulation for your course, it is important to keep in mind that there are two key categories of learning objectives that simulations can support: content and process (Asal and Blake 2006). Choosing which of these objectives is most important in the framework of your course is the first key decision you must make, although both objectives can be simultaneously met by a single simulation.

Simulations offer students an opportunity to comprehend and manipulate content knowledge in an active context that engages 
a variety of student learning styles and provides opportunities to experience the subject matter in a dynamic way (Michael 2006; Asal 2005; Hertel and Millis 2002; Lantis, Kuzma, and Boehrer 200o; van Ments 1999). The use of a simulation can, for example, enrich content related to structural dynamics in the international system by allowing students to experience power differentials between actors or explore the national interests that prevent agreement on issues that may initially seem simple to resolve. By assuming the role of one of the actors in a simulation, students have the opportunity to internalize interests and motivations in a way that reading or lectures simply cannot duplicate. The bases of intractable conflicts and unresolved issues become much clearer to students through the simulation experience, generating teachable moments for the instructor.

Simulations can also bring the complexities of process to the fore, which is especially useful for courses that focus on the intricacies of negotiation or institutional procedure. Courses dealing with American government can benefit from a simulation focused on the lawmaking process in Congress, for example, because students can experience firsthand the dynamics involved in each step of crafting and passing legislation. Courses that focus on negotiation theory or aim to provide a skill set associated with negotiation or mediation can benefit greatly from the inclusion of a consensus-building exercise that serves as a practical application of the subject. In this way, simulations serve as examples of applied theory, emphasizing the step-by-step process of negotiation and mediation in a way that static materials cannot.

Approached in this manner, simulations offer a laboratorytype experience for social science courses. Students are temporarily placed in the role of negotiator, a government official, or a representative of a nonstate organization and given the opportunity to work through complex issues in a safe environment. Failure in a real negotiation creates negative consequences for individuals and groups: failure in a simulated negotiation provides teachable moments and opportunities for active learning (Sasley 2010). The ability to unpack the motivations and strategies of the participants after the simulation ends, as part of the debriefing process, provides an opportunity for participants to reconsider their strategies and tactics and take lessons away from the exercise.

In terms of course objectives, content learning can be enhanced in the simulation preparation process, because there are stakes involved beyond grades. Although this phenomenon is understudied in the political science classroom, recent studies from other disciplines such as computer science (Wallace and Margolis 2007) and management (Attle and Baker 2007) have demonstrated the positive contributions that classroom competition can offer when applied in discrete exercises. Based on personal observations and student feedback, it is clear that students' competitive instincts provide a level of motivation to outperform their peers. When participating in teams, a strong incentive exists to not let teammates down, and this desire motivates students to be active and conscientious about their designated tasks. When students are assigned to subteams (by issue or other specialty), each individual must deliver on their assigned task or risk the failure of the entire team, which carries the very real threat of censure from their peers.

Finally, simulations give instructors a chance to vary the classroom experience and provide an opportunity for students with different learning styles to succeed. Many students are well- suited for success in a traditional lecture and exam format and therefore perform well in this environment. However, many others learn best when they can see processes in motion, or when they have the opportunity to apply knowledge while they are learning. Students who may sometimes appear to check out, or who are underperformers, often connect better with the applied nature of a simulation exercise, and very often, the leadership and coordination roles of simulation teams are assumed by students who may not have distinguished themselves in traditional classroom formats. Simulations are an ideal way to provide experiential learning options for these students, keeping them engaged in the course by providing opportunities for them to succeed. When course objectives are closely connected to the simulation exercise, the likelihood that these students will be successful overall greatly increases.

\section{BEFORE THE SIMULATION}

Effective use of simulations in the classroom starts during the syllabus creation process. It is important to select the right simulation to meet your learning objectives and connect the exercise to course content and outcomes. The most effective way of making this connection is to create your own course-specific simulation, as it will feature the exact content and process on your syllabus. However, simulation creation can be a difficult and timeconsuming process, and without some form of pilot testing, there are no guarantees that the exercise will hold together in a classroom environment. Many instructors choose to use simulations that have been created and tested by others for these reasons. This section details the options instructors have in choosing or creating simulations and provides some recommendations for student preparation before the exercise begins.

\section{Finding the Right Simulation}

There are three preliminary steps to choosing the right simulation for your course. The first step is finding or developing an exercise that connects to and supports your course content. Second, you must select the most appropriate format for the simulation from the many options available. Finally, it is necessary to find an exercise that fits into the schedule and time available within the course. There are many possible combinations of these choices, so at each step, it is important to consider the course objectives to ensure that the end result will serve your specific needs. You should identify these objectives before evaluating possible exercises, as a means of both limiting your search and forming clear evaluation criteria as you consider options. For example, if you are teaching a course on economic development in Africa, it makes little sense to look at U.S. Congress simulations.

This section presents the most common options for creating simulation exercises using four distinct format options, which are also summarized in figure 1. Although these options are presented as a simple dyadic choice, it is important to note that there are shades of variation within each option, and it can often be effective to combine these choices if time and resources permit. The combination of options can be extremely worthwhile in more complex exercises for drawing out different communication, research, and interaction styles for students or providing opportunities to reconsider information from different perspectives. For example, you may find it appropriate to conduct an exercise with a mixture of online and face-to-face delivery methods to give 


\section{Figure 1}

\section{Decision Stages for the Use of Classroom Simulations}

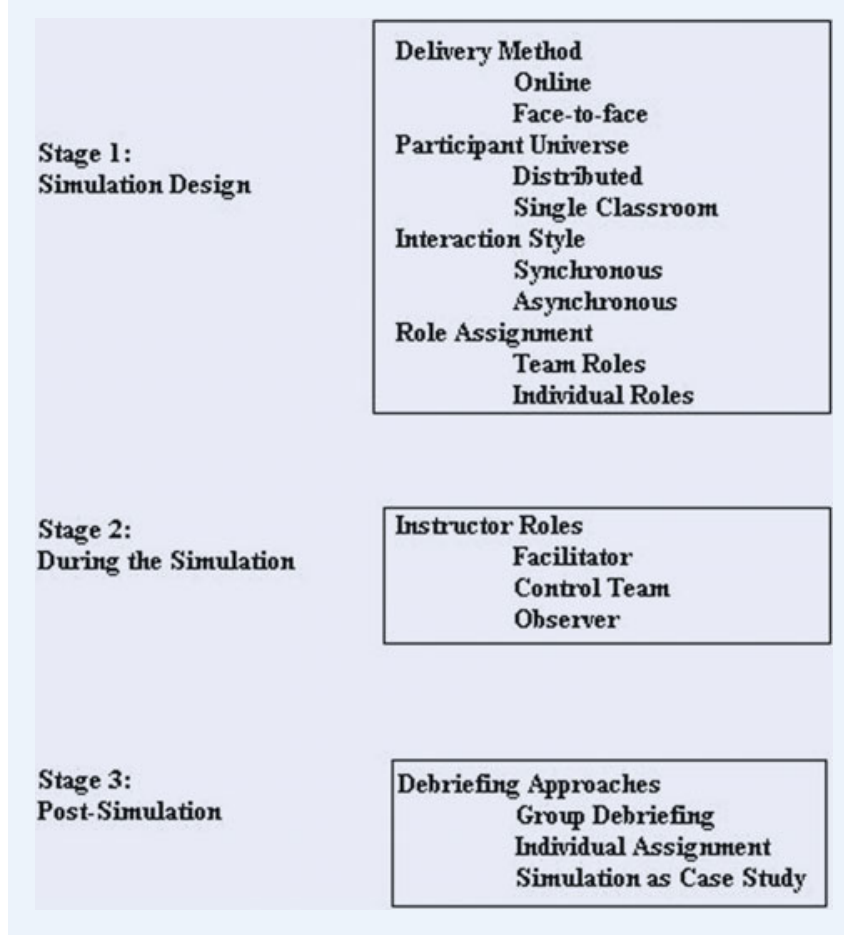

students with different communications styles the chance to lead their group.

\section{Delivery Method}

Although there are variations within each type, simulations are delivered through methods that can be best categorized as online or face-to-face formats. While both can be effective and each has its pros and cons, the choice of delivery method has an effect on the overall atmosphere of the exercise. Simulations can be run entirely in one of these formats or may use a combination of delivery methods if time, space, and resources permit.

The use of technology as an intermediary in online simulations can remove interpersonal aspects of negotiation (e.g., body language, personal charisma) from the mix, forcing a focus on clear written communication. The software used (whether a dedicated software tool or simple e-mail) will generate an archive of the negotiation that can be used in debriefing or student reflection papers. In addition, because students generally have access to their own computers or computer labs on campus, it is possible to schedule the majority of the simulation outside of regular class times so that instruction can continue during the exercise.

However, online simulations also have drawbacks that should be balanced against their positive aspects. Students who are uncomfortable with technology or have limited access to the Internet may not be able to participate at the same level as their peers. This limitation will vary based on lab availability or student characteristics at your institution (e.g., commuter or working students may have limited access to campus computer labs). Instructors must have a relatively high level of comfort with technology, because even the most seemingly intuitive online system will require some introduction, training, and support for students by the instructor, and the instructor must be prepared to troubleshoot and respond to student questions. Finally, there is an inherent bias in using computers in this fashion that should be considered. Some students are going to be able to maximize the technology-for example, by using html coding to make their messages more visually appealing or leveraging their experience with advanced online research tools-and this difference in skill level will result in a hierarchy among teams. (One useful approach to this problem is to identify these students in advance and assign them to different teams.)

Face-to-face exercises are the quickest activities to create and require the least investment for instructors in terms of resources (e.g., fees for software development or customization). Some of the positive aspects of this approach are that students can develop their public speaking skills, hone their use of visual aids (e.g., charts, presentation software), and experience the procedural aspects of a formal conference environment. This format also creates much stricter time constraints for negotiations, which forces students to be much more focused and careful in their use of time during the session. Although this restriction could also be seen as negative, it presents strong incentives for teams to prepare in advance, since they will not be able to conduct additional research or internal discussion during the session. Finally, the instructor has complete autonomy in scheduling the exercise, because there are not other parties involved, so exercises can be concluded or extended as progress dictates.

On the other hand, face-to-face exercises also bring some potential pitfalls to the table. Because all students must be present for the simulation and the logistics of bringing together students from different locations can be complex and expensive, these activities work best in a single classroom. This constraint can limit the variety of perspectives brought to the table, particularly since students with minority opinions may feel less willing to express them in a face-to-face setting. In-person simulations generate no archive of interactions; details will be lost unless arrangements are made to record the proceedings or someone is designated to take notes, so debriefing must be done immediately after the exercise to ensure maximum retention of these points. Finally, instructors must either allocate class time to the exercise or undertake the difficult task of aligning schedules and reserving space outside of class for the exercise. Scheduling is not a major factor with a one-session exercise, but for longer and more complex exercises, it can be a significant burden for the instructor.

\section{Participant Universe}

The participant universe for a simulation is defined by who is taking part in the exercise-either a single-classroom or a distributed format (i.e., multiple classes or locations). Although this article specifically focuses on individual courses, it can often be desirable to format an exercise to include multiple classes or locations. For example, a combined exercise involving a political science and an economics class would allow students to gain new knowledge and perspectives by linking the two disciplines. Similarly, it would also be possible to combine these two approaches by separating the negotiation levels (e.g., breaking down a twolevel game) or adding a single-classroom pre- or post-simulation exercise to the distributed simulation.

Distributed exercises offer the most potential for the expression of multiple opinions and values, because student teams can 
be drawn from a variety of locations, backgrounds, and experiences. Many more teams can take part in a distributed exercisebecause the potential pool of participants includes classes from around the world, it is theoretically possible to create a simulation involving dozens, even hundreds, of parties (e.g., a Model United Nations exercise). This broadened scope can often produce more complex and creative outcomes as students seek to reconcile often divergent opinions. Finally, because they are engaging with peers from other institutions, students tend to take the exercise more seriously and exhibit competitive traits to prove that their school is more capable. It can be effective, for example, for students to face academic, geographic, or athletic rivals in order to create a powerful motivation for good performance.

However, distributed exercises also pose some challenges in terms of time, space, and expense. It can be very difficult to schedule a distributed exercise, given the variation in holiday and break scheduling. For example, scheduling an exercise with other instructors in the spring is often nearly impossible as a result of varying less likely to be represented. In part, this homogeneity may be due to a lack of awareness of different perspectives, but more often, it stems from students' tendency to defer to the authority of the instructor in terms of perspective and approach. The roleplay aspect of the exercise can be more difficult to maintain within a single class, because students already know each other. They may struggle to stay in their roles or maintain the formality required for an effective exercise. (In other words, outbreaks of silliness have been known to occur.) Finally, the perceived stakes are often lower for students in a single-classroom exercise, since the sense of competing with others is less acute.

\section{Interaction Style}

Interaction style refers to the mode of communication, generally distinguished between synchronous (simultaneous) and asynchronous (serial) forms. While most simulations use some combination of these two formats, it is possible to use them independently either throughout or in separate phases of an exercise. In this

\section{The use of technology as an intermediary in online simulations can remove interpersonal aspects of negotiation (e.g., body language, personal charisma) from the mix, forcing a focus on clear written communication. The software used (whether a dedicated software tool or simple e-mail) will generate an archive of the negotiation that can be used in debriefing or student reflection papers. In addition, because students generally have access to their own computers or computer labs on campus, it is possible to schedule the majority of the simulation outside of regular class times so that instruction can continue during the exercise.}

spring break times between late February and late April, which leaves windows only at the beginning of the semester before students are prepared or the end, when they may be already checked out. It can also be very expensive to arrange travel and physical space for a distributed face-to-face exercise. Online simulations can alleviate this problem, although a group debriefing of all participants remains an obstacle. Third-party distributed exercises may also have different goals or agendas than the instructor has and may even conflict with intended course outcomes. Finally, variations in preparedness and course goals among the locations can produce an uneven experience in terms of quality and learning outcomes.

Single-classroom exercises are by far the easiest simulations to arrange and supervise, because the entirety of the exercise can take place under the supervision of the instructor. Since everyone is from the same class, they all have had the same preparation and expectations prior to participating. This uniformity helps keep the exercise focused and build momentum, because students can refer to information they have all previously learned and can expect everyone to understand. At the end of the exercise, the teacher can easily debrief all participants in a single location, either immediately after the conclusion of the simulation, or after a period of individual reflection.

Some of the drawbacks of the single-classroom simulation are the same as its attributes. Although common preparation and expectations can enhance speed and focus, divergent views are far section, I consider them separately to draw out their distinct characteristics.

Synchronous interactions occur in real time, with all parties sending and receiving communications (verbal or written) either simultaneously or in turns. When using this style, all parties have the ability to observe and take part in all communications, and the instructor can observe these interactions as they occur. This approach forces students to focus on quick assimilation and analysis of information to respond to their peers, and therefore encourages the development of efficient team processes. This format is particularly effective for crisis or other time-sensitive simulations in which the accuracy and timeliness of response is important. Although synchronous interactions are ideally suited for face-toface simulations, approaches such as scheduled conferences or limited negotiation times can also be incorporated into online exercises.

There are many topics or situations in which synchronous communication can detract from the experience, however. In particular, when used alone, this style tends to produce less complex outcomes, because communications tend to occur in a more linear fashion. This simplifying effect is a product of both the difficulty of holding more than one conversation at once and the natural tendency for discussions to focus more narrowly on one topic at a time. The result is generally an outcome with less opportunity for issue linkage or detailed implementation features. Less time remains for reflection and internal team discussion, as time 
taken away from the group generally means missing out on group negotiations.

Despite the appeal of synchronous communications, in many cases, an asynchronous model can be more effective. Because a reply to a statement does not need to occur immediately in this model, groups have time for reflection, team discussion, or private consultation with allies about content and strategies. Communications tend to be more complex, since there is more time to craft messages and opportunities that include greater specificity and detail. If the instructor has access to these messages, he or she also has more opportunity to provide feedback and teachable moments during the exercise. This approach is well-suited for longer or more detailed simulations, or simulations that deal with particularly complex issues.

However, while asynchronous communication allows for more reflection and detail in responses, students may not always use the time constructively. Students have more opportunities to check out of simulations when they are not constantly engaged, or if they feel they are not receiving an adequate amount of communication. Instructors may struggle to monitor exchanges in the absence of a designated messaging system or framework, leading to lost teaching opportunities and less thorough debriefing. The teams must accept the responsibility for coordinating their response mechanism for messages, including conducting internal discussions and crafting their reply, and teams that are poorly organized can fall behind quite quickly.

\section{Role Assignment}

Students can undertake roles in a simulation exercise either as teams or individuals. In my experience, teams are far more effective, because they add the additional layer of internal negotiation into the exercise and build valuable collaboration skills, but there are situations (such as experimental or training simulations) in which individual roles make the most sense. Although exercises available from vendors generally specify how roles should be distributed, teachers should still consider the relative merits of each approach.

Team role assignments, in which students are assigned in groups to portray a single role, offer a number of advantages. As indicated previously, these exercises allow for negotiations within the team, emphasizing collaborative aspects of international relations. This structure offers students the option of specializing in tasks or issues, allowing them to emphasize their strengths or develop new ones. This format is useful for large classes; for example, it can be effective to divide students into teams by discussion section. Small classes can be divided into teams or can form a single team (divided into issue specialties as appropriate) in a distributed simulation as well.

Placing students in teams can provide a temptation to freeride within the group, which is often exacerbated by the reluctance of other students to confront the offenders or complain to the instructor. Peer pressure can alleviate this issue to some degree, and confidential peer grades that factor into student grades for the exercise are often quite effective as well. Teams can occasionally produce internal conflict, requiring instructor intervention to resolve and to ensure that students on the losing side of the disagreement maintain engagement with the larger group. It can also be challenging to assign individual grades for team work, although individual assignments within the exercise, peer grading, and observation by the instructor can alleviate this difficulty.
Individual roles are most effective in small groups, both because it is easier to observe each student and because each role is likely to have more relevance within the exercise. With individual roles, each student is explicitly accountable and consequently has a greater investment in the outcome. Grades are much easier to assign to individuals than to groups, and students will generally learn the most in terms of breadth (although not always depth) about the subject matter. This approach can also produce greater diversity of opinion, since each individual must be actively involved.

Simulations with individual roles do, however, tend to be dominated by a few personalities. It is difficult to ensure that all parties have an opportunity to be heard in this case, because there are no team members to balance the dominant personalities. A single student absence or underperformance can disrupt the entire exercise, particularly if that student represents a critical role. Preparation for a simulation of this type is also more complex, because each role must have roughly equivalent supporting material and relevance within the exercise. Although it is usually simple to identify five or six roughly equal roles on a topic, it is significantly more difficult to find twenty or thirty that are equivalent and distinct.

\section{Final Thoughts on Simulation Selection}

Selecting the most appropriate format from these options requires you to think through both your expectations for learning outcomes and the level of engagement that you expect from your students. If you want a one-day simulation experience and do not have ready access to a computer lab, it makes sense to use a simulation that is face-to-face, single classroom, and synchronous. If you want an exercise that addresses semester-long content, it may be better to choose an online, asynchronous approach. A smaller class size is often well-served by distributed exercises that increase the number of parties and perspectives represented. It is important to keep in mind that even an exercise that matches your content objectives will not be particularly effective if the format of the exercise does not fit your available time, technology, and logistical resources, so you may need to revise these materials for your particular situation.

A final, although certainly not inconsequential, question for the instructor looking for an off-the-shelf exercise is whether you should pay for a simulation exercise from a vendor or seek free options. A variety of providers can be found online by searching for specific topics: lists of simulations can be found in a number of places such as APSAnet (http://www.apsanet.org/content_15404.cfm), and many journals now include simulations as part of their content. As a general rule, free simulations require more instructor preparation in terms of printing materials and setting up the exercise, and they generally offer minimal, if any, support. These exercises are good options for experienced instructors or teachers with limited access to departmental resources, and they are a cost-efficient way of experimenting with simulations or learning about simulation design in preparation for creating your own. Paid simulations can be relatively costly, but they offer staff support and extensive instructor guides, and provide all necessary materials for the classroom. Online paid simulations (e.g., exercises offered by the ICONS Project at the University of Maryland, http:// www.icons.umd.edu) offer a specialized online simulation interface in addition to materials. Instructors are even using online "virtual worlds" (e.g., Second Life) for classroom applications such 
as structuring environments and scenarios for distance learning and specialized classroom exercises (Foster 2007; Childress and Braswell 2006).

\section{Pre-Simulation Student Preparation}

Once a simulation exercise has been selected, you should allocate ample time for student preparation, particularly introducing the content, format, and expectations and allowing time for research and team meetings. Whenever possible, students should be encouraged to connect course content with the simulation in the lead-up to the exercise. This approach encourages active learning in the pre-simulation phase by allowing students to apply knowledge to a concrete task and also increases the likelihood that they will be well-prepared for the exercise itself. I have had success in the past in using simulations as capstone experiences near the end of the semester, allowing students to accumulate learning artifacts through assignments that they can actively apply to the exercise at the end of the course.

There are many ways to link the exercise to content, and this decision should be guided by considerations of how your content fits within the framework of the exercise, and vice versa. One effective approach is to link the issues in the simulation exercise with course content in discrete units-that is, the issue areas in the simulation can become an organizational tool for course content. Having students give classroom presentations on this content, particularly from the perspective of their assigned role, can further increase their learning. Another approach is to integrate simulation preparation into written class assignments and assessments. Assignments and tests that include simulationspecific material serve to emphasize the importance of the exercise as well as increase preparation opportunities. These two options are not mutually exclusive and, in fact, complement each other very well.

Depending on your needs, it may not be possible or desirable to create a course that revolves around a simulation exercise, particularly if you are an instructor new to simulation. However, some level of integration between content and simulation is important for student success in a simulation exercise. As a general rule of thumb, based on personal experience, the best ratio of preparation to simulation is approximately 1:1-a one-day exercise can generally be adequately prepped in one day, while a more complex, several-week-long simulation may require several weeks of content and team preparation. However, much of this preparation can be assigned outside of class time in the form of research papers, readings, or team meetings, and because the simulation will be matched to course goals, this preparation phase will serve these ends as well.

Simulation teams should spend time together in meetings to work through their strategies and tactics. This approach helps overall preparation (content and role information) and allows students to develop a specific team approach for the exercise. Preparation meetings also give individuals a chance to hone their group-work skills by requiring them to reach consensus as a team prior to the start of the exercise. To be effective in a simulation, a team must speak with one voice and maintain a consistent approach to other teams, regardless of who is involved in an interaction at a given time. This internal team negotiation is a key learning outcome for team-based simulations and gives students necessary experience for future academic or professional endeavors.

\section{DURING THE SIMULATION}

Effective simulations should be driven by students rather than the instructor, even when the instructor assumes an active role in the exercise. Pre-simulation activities are designed to prepare students to know what to do in the exercise and how to accomplish it. Because of this expectation, once a simulation begins, it is tempting for an instructor to simply step aside and allow the exercise to unfold without further input. This inclination may be particularly strong when the simulation is distributed, since the general day-to-day proceedings are often led and monitored by a third party. Although it is important to not stifle student learning and creativity by overmanaging the exercise, the instructor should still remain engaged on a daily basis to maintain quality and support learning outcomes.

The role of the instructor during a simulation is to encourage, monitor, and guide learning outcomes for students. Simulation exercises can consume as little as one class session to as long as an entire semester, so the number of opportunities for reinforcement and interaction during the exercise vary. For short simulations, these opportunities are more limited and generally occur during the activity itself. During an in-class simulation, instructors may find it useful to call time outs or schedule breaks at certain points to emphasize specific concepts or allow students to refocus their efforts. Occasionally stepping out of their roles (even in real-time) can be beneficial for students, as they can reflect and evaluate their progress to that point.

During longer exercises, however, it is possible to use class time as a means of mutually reinforcing the objectives of the simulation and the class. A class session on negotiation tactics during a simulation allows students to factor new information into their approaches and can serve to increase the overall complexity and sophistication of the exercise. This mixed approach also allows students to immediately apply knowledge, because they can use it in context during their next simulation session. Class time can also serve as a common meeting place for simulation participants, with even a few short minutes at the end of a class serving a valuable team organization function. For example, these few minutes of class time can allow students to arrange their own simulation meetings.

An instructor can assume many roles during a simulation exercise, although I discuss three main categories here. These roles may be determined less by instructor choice than by the needs of the simulation, because class size and exercise structure may require the instructor to emphasize one role or another. However, some general guidelines should be followed for all of these approaches, regarding cautions as well as opportunities for the instructor to increase the learning payoffs from the exercise itself. These role categories (facilitator, control team, and observer) are described here individually, although they are not mutually exclusive. Instructors often find themselves taking on more than one of these roles during a given exercise, usually simultaneously.

\section{Facilitator}

In nearly all cases, the instructor will undertake a facilitation role during the exercise. This role could be limited to simply serving as a timekeeper or ensuring that sessions start on time and exercise procedures are followed. However, depending on the construct of the exercise, the facilitator role could include moderation, mediation, or even arbitration roles. Ideally, these tasks should be assumed by students, but if this is not feasible, the instructor 
should take measures to ensure that this allocation does not interfere with the simulation. For example, you might create a structure that compartmentalizes your role by limiting your availability or requiring students to produce a substantive agreement before submitting it to you for arbitration.

Regardless of your function, you should create a clear set of guidelines and expectations for this role and share it with your class. These guidelines are also for your own use as the exercise unfolds and should be referred to often. During a simulation, it is always tempting to expand your role by working with students or offering advice, but you should avoid interfering whenever possible, because students can often perceive an instructor's offhand opinion as an authoritative declaration. If the exercise becomes too instructor-focused, much of what makes a simulation unique can be lost. Less is more when it comes to direct instructor involvement in a simulation exercise.

\section{Control Team}

There are occasions on which instructors find that they must adopt an active role as a control team, as a result of class size or the specific characteristics of a given role. This involvement may be necessary when a particular role is more powerful than others and could upset the balance of the exercise, requires specialized knowledge beyond the scope of the course, or has such a limited part in the exercise that it would require little student preparation or execution. Ideally, students would not know that anyone is serving as a control team in the exercise, although in most cases, this concealment is impossible. (Hiding the role is easier with an online exercise, although it is difficult to sustain the deception.) If a control team is necessary, using a teaching assistant or a student not currently enrolled in the course (e.g., part of an independent study, paid student work, or extra credit in another class) is preferable to having the instructor take the role. If the use of an outside individual is not possible, then caution is recommended to preserve the integrity of the exercise. In this situation, the same recommendations from the facilitator role are applicable. If your participation is known, it is important that you and your students have a set of guidelines regarding the capabilities and limitations of your role, and that all parties adhere to these rules during the exercise. You should be aware that while all roles may be created roughly equal, not all participants are. As the instructor, your opinions and preferences will carry far more weight than those of other teams, so you should make an effort to ensure that your presence does not unduly influence other roles.

\section{Observer}

The most important functions of the instructor during the exercise are to monitor the simulation to identify issues and problems as they arise, intercede if necessary, and collect material for the post-simulation debriefing. Regardless of any other roles that the instructor may assume during the simulation, the observer is the one role that the instructor must always take. By following the exercise as it unfolds, the instructor is able to provide useful input for students and advice when asked. More important, however, is that the instructor can take advantage of teachable moments as they arise. For example, in the event that a team's strategy has proven unsuccessful, you can encourage that team to reflect on events and persuade them to adjust their approach during subsequent classes. A quick response in these cases can prevent a team from disrupting the exercise or completely checking out.

Some other objectives for instructors can be to monitor students' communication styles and application of course content. The incorporation of concrete simulation examples of why teams were or were not successful will enrich the debriefing process. In addition, occasional interventions may be appropriate to reinforce course goals or provide encouragement to student teams. Instructor involvement during the simulation will emphasize the importance of the exercise as well, keeping students focused and minimizing temptations for free-riding within the group.

Finally, for longer exercises, it is useful to provide students with time to meet in their teams to discuss their progress and address obstacles that may have arisen in the simulation. These meetings can occur in or outside of class, or even through virtual means such as an online class forum or other chat venue. Some ways of managing this process are by requiring a written summary or online transcript of the meeting, or setting aside time during office hours to meet with the group. In this way, students can mutually reinforce course content for each other, and the instructor can provide additional input and encouragement as appropriate.

\section{POST-SIMULATION}

Once the simulation has ended, it is the role of the instructor to tie the experience to the course content as closely as possible. The debriefing process is in many ways the key to the entire simulation process, as it is the piece that connects the student-driven, active-learning component back to the instructor-designed course content and learning objectives. Provided that you choose a simulation that connects with your course content and are engaged during the exercise itself, you should be able to construct a debriefing session that emphasizes your learning objectives in a clear and powerful manner. An effective debriefing emphasizes learning outcomes from the exercise and serves to reconnect students with the traditional classroom, providing a bridge between the two.

It is important to note that the post-simulation period is referred to here as a process, rather than a discrete event or activity, to emphasize that it should be seen as more than just a single element. The group format and interactive nature of simulations present multiple layers of complexity that can be unpacked and used for learning opportunities. To take full advantage of all aspects of this experience, you should allocate sufficient time to the postsimulation stage and use a variety of approaches. Several useful methods for the debriefing process are presented here that can be used to maximize the effectiveness of the exercise.

\section{Group Debriefing Session}

The first part of the debriefing process (and generally the stage most anticipated by students) is often the group debriefing session. This should be conducted as quickly as possible after the conclusion of the exercise, and ideally, immediately after it ends, so that recollections are fresh and students remain in their assigned roles. This approach is often referred to as a "hot" or "flash" debrief, because participants have just stepped out of the simulation. Although these sessions can occasionally become tense, the instructor can redirect this passion to increase student understanding of the complexities of the subject matter. (For example, they 
could draw lessons or linkages from their frustrations to real-life examples of conflict resolution.) If the debrief is not immediate, it is helpful to take a few minutes to recap the exercise and ask students to assume their roles in their group once again.

The first aspect of the group debrief should be an opportunity for students to vent or express their general feelings about the exercise. Frustration and excitement about the results are natural outcomes, and students should have an opportunity to express these reactions at the beginning of the session. Encouraging this feedback first allows students to decompress a bit and also reveals particular aspects for discussion during the remainder of the session. While the instructor must maintain order in the classroom, some back-and-forth between teams is normal in this phase of the group debrief and can be directed into positive learning opportunities. For example, confusion about the behavior of another team can be used to illustrate differences in preferences expressed by rational actors in a negotiation context. This kind of dialogue is often most effective if the instructor steers the discussion to roughly follow the narrative of the simulation, focusing on clear decision points and actions taken by the parties.

A direct outcome of the venting phase can be insight into the motivations, positions, and interests of other parties. Teams can explain or defend their actions in the context of their assigned roles and their outcome preferences for the simulation. Once the simulation has ended, students should be encouraged to share confidential information about their roles, such as data to which they alone had access or the results of their own research and planning. This stage allows students to talk about their team preparation and strategies for the exercise and affords an opportunity for the instructor to relate these elements back to course learning objectives. In particular, discussions about the difficulty that parties face in cooperating or reaching formal agreements will fit into this discussion well, since the motivations of the various parties are transparent and available for questioning by others.

At the end of this session, it is useful to engage in a discussion about group processes, including the difficulties encountered by individual students in working with a group and the strategies that they used for internal organization and interactions with other teams. As students relate experiences within their groups, they can be connected to specific content areas and group dynamics issues, including topics such as aggregation of interests and general group-work skills applicable to the workplace. This discussion serves to emphasize useful skills and approaches to working within groups, as well as to move the focus back to the level of individual students. A discussion of the process of the simulation can be included here, with a focus on student learning at each step of the process, including preparation and various simulation phases. It can be helpful to ask students to relate these aspects of the exercise to their program of study or future academic and professional goals (e.g., how their internal team discussions might relate to their courses in business or help prepare them for law school). In other words, this discussion seeks to emphasize the takeaways from the experience, in addition to content and process knowledge.

The final element of the group debrief should be an instructorled discussion that specifically relates the exercise back to course content. This discussion serves as a way to fit the exercise within the framework of the overall course and to allow the instructor to resume his or her role as classroom leader. Ideally, this wrap-up discussion should move from simulation-specific examples to increasingly more general applications to encourage students to leave their roles behind and return their focus to classroom outcomes and content. Key concepts from the simulation can be emphasized by taking events from the exercise and attaching names to them (e.g., log-rolling in a government simulation or north-south power differentials in an international relations simulation) or making comparisons with cases covered in class. This approach can serve as a bridge to reconnect the exercise to the rest of the course and return to a more traditional classroom format.

\section{Individual Assignment}

After working in a group for a period of days or even weeks, most students are eager for an opportunity to offer their own reactions to the exercise. An individual assignment, generally in the form of a short reflection paper, is a good forum for these opinions. Instructors should link this paper to course objectives and teachable elements of the exercise itself, such as those concepts related to specific outcomes or events that took place. The length of the paper should be correlated to the length of the exercise, but it should ideally be long enough to focus on both process and content issues. This paper could be a formal research paper, although a simple reaction paper drawing from student experience rather than cited works is generally more effective. The instructor should provide a list of questions related to process and content, including elements such as team preparation, internal team organization, negotiation strategies and tactics, perceived relations to course content, and personal reactions to provide guidance to students. It is recommended, although not necessary, that the instructor include an element of analysis in this assignment, either by asking students what they may have done differently, given what they now know, or how they might apply their experiences to future situations. Finally, this assignment is a good opportunity to ask students to explain what they did individually within their groups during each phase of the exercise. While the instructor should have a good idea of what each student contributed, this can serve to either reinforce or fill gaps in this observation.

\section{Simulation as Case Study}

Provided that the simulation takes place early enough in the course, it is possible to use this exercise as a form of case study for future class material. Unlike traditional case studies, the simulation exercise is a shared experience that all students take part in and of which they have an understanding that is both detailed and complex. One particularly effective pedagogical approach is the use of specific examples from this experience to illustrate concepts or compare to other cases. I have found it very effective, for example, to relate the simulation exercise to concepts introduced later in the course, such as components of game theory, which can seem somewhat abstract to students. The ability to place names (e.g., "iterated games" or "brinksmanship") on behaviors that students have already experienced and strategies that they have already used is a powerful pedagogical tool for an instructor.

It can also be useful to use the actual episode or setting on which the exercise was based as a case study separate from the simulation itself. The research that students conducted in preparation for the exercise can serve as a starting point for a more sophisticated examination of the actual case, essentially building on what they have already done with additional information drawn from new course content. Although it is possible to overuse a case 
in this manner, a great deal of value lies in the occasional use of this approach to provide an increasingly complex understanding of a case study.

\section{Assessing the Impact of Simulations}

Assessing the impact of simulation exercises on student learning is difficult, given that a proper research design for doing so does not merely assess learning within a course, but also compares courses with simulations to identical ones without simulations. Because most instructors rarely teach a course more than once per semester, most of the evidence up to now has been anecdotal or, at best, has consisted of comparisons of different iterations of the same course before and after simulations were adopted. Both of these research designs are admittedly problematic, given the limitations of the data and potential intervening variables such as differences in student cohorts. These limitations are often cited in criticisms of simulations, as it is difficult to demonstrate a return on the investment when most of the evidence is based on anecdotal or proxy measures such as teaching evaluations, registration for these courses, or student feedback.

Efforts to quantify the effect of simulation often generate seemingly contradictory results, showing high student satisfaction but negligible testing outcomes (Raymond 2010). However, a growing body of empirical support is demonstrating the positive effects of simulations in the classroom, beyond their effect on grades. Recent work demonstrates that simulations can improve student understanding and retention of content (Yoder and Hochevar 2005), increase student interest in the subject matter more generally (Shellman and Turan 2006), and even enhance student ability to gain admittance to and succeed in graduate school (Kember and Leung 2005). Pre- and post-unit tests can be useful tools in establishing the effectiveness of simulations versus other pedagogies in individual classes by comparing gains in units with and without simulations. Although this approach remains a difficultto-quantify aspect of teaching political science, evidence is accumulating in support of simulations.

\section{CONCLUSION}

The many benefits of active learning techniques such as simulation exercises have been the focus of numerous books, studies, and articles. The use of simulation exercises in the political science classroom in particular provides opportunities for active learning often absent from the social sciences, and this approach can dramatically reinforce course objectives. However, teaching time is at a premium for instructors-and this limited time is often reduced by holiday and weather-related closures, as well as other factors outside the instructor's control. Devoting time to a simulation exercise requires a commitment of this limited resource, in preparation as well as classroom instruction time. This time commitment can seem particularly overwhelming to teachers who have never used simulations, and even instructors with simulation experience may be reluctant to experiment with new exercises or approaches.

Although these concerns are understandable, the return on this investment can be maximized through careful planning and effective exercise management, improving the classroom experience for both student and instructor. This article attempts to address these concerns with an overview of the stages of an effective classroom simulation exercise and step-by-step linkages to ways that simulations can support course content and learning objectives. Rather than serving as detours or distractions from course goals, simulation exercises can form the core of a course by supporting existing content and engaging students in active learning both before and after the exercise. Although simulations will always require some allocation of class time, this article offers strategies that can be used to maximize and, in many cases, multiply the returns on this time. By focusing on making the right decisions at each stage of the decision process, the costs in time and effort required for a simulation exercise can be dramatically outweighed by its classroom benefits.

\section{NOTE}

I would like to thank Audrey Tettah and my other former colleagues at the ICONS Project for their invaluable advice in framing this piece, as well as my fellow participants at the 2008 APSA Teaching and Learning Conference for their constructive input.

\section{REF EREN CES}

Asal, Victor. 2005. "Playing Games with International Relations.” International Studies Perspectives 6: 359-73.

Asal, Victor, and Beth Blake. 2006. "Creating Simulations for Political Science Education." Journal of Political Science Education 2 (1): 1-18.

Attle, Simon, and Bob Baker. 2007. "Cooperative Learning in a Competitive Environment: Classroom Applications." International Journal of Teaching and Learning in Higher Education 19 (1): 77-83.

Childress, Marcus D., and Ray Braswell. 2006. "Using Massively Multiplayer Online Role-Playing Games for Online Learning.” Distance Education 27 (2): 187-96.

Foster, Andrea L. 2007. "The name assigned to the document by the author. This field may also contain sub-titles, series names, and report numbers.Professor Avatar: In the Digital Universe of Second Life, Classroom Instruction Also Takes on a New Personality." Chronicle of Higher Education 54 (4): A24.

Hertel, John P., and Barbara Millis. 2002. Using Simulations to Promote Learning in Higher Education. Sterling, VA: Stylus.

Kember, David, and Doris Y. P. Leung. 2005. “The Influences of Active Learning Experiences on the Development of Graduate Capabilities." Studies in Higher Education 30 (2): 155-70.

Lantis, Jeffrey S., Lynn M. Kuzma, and John Boehrer, eds. 20oo. The New International Studies Classroom: Active Learning, Active Teaching. Boulder, CO: Lynne Rienner.

Michael, Joel. 2006. "Where's the Evidence that Active Learning Works?" Advances in Physiology Education 30: 159-67.

Raymond, Chad. 2010. "Do Role-Playing Simulations Generate Measurable and Meaningful Outcomes? A Simulation's Effect on Exam Scores and Teaching Evaluations." International Studies Perspectives 11 (1): 51-60.

Sasley, Brent E. 2010. "Teaching Students How to Fail: Simulations as Tools of Explanation." International Studies Perspectives 11 (1): 61-74.

Shellman, Stephen, and Kürşad Turan. 2006. "Do Simulations Enhance Studen Learning? An Empirical Evaluation of an IR Simulation.” Journal of Political Science Education 2 (1): 19-32.

Van Ments, Morry. 1999. The Effective Use of Role-Play: Practical Techniques for Improving Learning. London: Kogan Page Limited.

Wallace, Scott A., and Jason Margolis. 2007. "Exploring the Use of Competitive Programming: Observations from the Classroom." Journal of Computing Sciences in Colleges 23 (2): 33-39.

Yoder, Janice D., and Catherine M. Hochevar. 2005. "Encouraging Active Learning Can Improve Students' Performance on Examinations." Teaching of Psychology 32 (2): 91-95. 


\title{
American Political Science Association
}

\section{eJobs: Your Online Resource for Political Science Careers and Candidates}

\begin{abstract}
APSA's eJobs is a year-round, online resource for political science employment opportunities and job candidates. It contains the most comprehensive online database of political science jobs, is updated daily with new job listings and candidate resumes, and is fully searchable by field of interest, name of employer/candidate, region, keyword, position, salary, type of institution, and most recent listings.
\end{abstract}

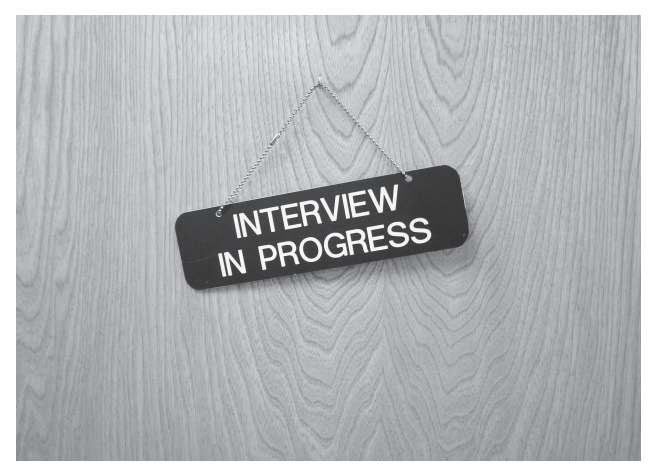

\section{How Does eJobs Work?}

\section{Job Candidates}

APSA members can access all open job listings and post their resume online to share with prospective employers by logging in to www.apsanet.org with your MyAPSA member login. The service is free to and offered exclusively to APSA members. Only APSA members can access the job listings or post their resumes to share with prospective employers. We encourage non-members who are interested in the service to join APSA now.

\section{Employers}

Employers who are APSA Departmental Services Program (DSP) members may post an unlimited number of job listings to share with prospective candidates and may search the available resumes free of charge. Employers who are not DSP members may advertise positions for a fee. Non-member employers who have posted a job listing can also access the candidate resumes.

Member and non-member employers can access eJobs by logging in to www.apsanet.org with their DSP login. Non-member employers: for more information on the DSP, contact dsp@apsanet.org.

\section{Printed Job Listings in the PS: Political Science and Politics Supplement}

APSA prints eJobs job listings in a supplement to the APSA journal PS: Political Science \& Politics. The supplement accompanies PS each quarter (January, April, July and October) and includes job listings, upcoming conferences, tables of contents of forthcoming APSA journals, and other news in the profession. The print listing is free of charge to employers who post job listings on eJobs.

\section{www.apsanet.org/ejobs}

